\title{
Macroscopic findings in collagenous colitis: a multi-center, retrospective, observational cohort study
}

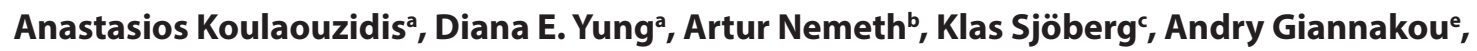 \\ Raheel Qureshif, Leonidas Bartzis ${ }^{a}$, Morna McNeilld, Gabriele Wurm Johansson ${ }^{b}$, Alfredo J. Lucendog, \\ Paul Fineron ${ }^{d}$, Ken C. Trimble ${ }^{a}$, Athar Saeed', John N. Plevris ${ }^{a}$, Ervin Toth ${ }^{b}$ \\ The Royal Infirmary of Edinburgh, Edinburgh, Scotland, UK; Skåne University Hospital, Malmö, Sweden; Western \\ General Hospital, Edinburgh, Scotland, UK; Open University of Cyprus, Nicosia, Cyprus; Queen Elizabeth Hospital, \\ Gateshead, England, UK; Hospital General de Tomelloso, Spain
}

\section{Abstract}

Background Collagenous colitis (CC) is by definition a histological diagnosis. However, colonoscopy often reveals characteristic endoscopic findings. The aim of this study was to evaluate the frequency and type of endoscopic findings in patients diagnosed with CC in 4 participating centers.

Methods This was a retrospective study; the databases of 2 university hospitals in Edinburgh (Scotland) and Malmö (Sweden), and 2 district general hospitals in Tomelloso (Spain) and Gateshead (England) were interrogated for patients diagnosed with CC between May 2008 and August 2013. Endoscopy reports and images were retrieved and reviewed; data on lesions, sedation, bowel preparation and endoscopist experience were abstracted. Categorical data are reported as mean $\pm \mathrm{SD}$. Fischer's exact, chi-square and $t$ (unpaired) tests were used to compare datasets. A two-tailed P-value of $<0.05$ was considered statistically significant.

Results 607 patients (149 male, mean age $66.9 \pm 12.25$ years) were diagnosed with CC. A total of $108 / 607$ (17.8\%) patients had one or more suggestive endoscopy findings: i.e., mucosal erythema/edema, 91/607 (15\%); linear colonic mucosal defects, 12/607 (2\%); or mucosal scarring, 5/607 (0.82\%). For colonic mucosa erythema, there was no difference in the odds of finding erythema with the use of different bowel preparation methods $(\mathrm{P}=0.997)$. For colonic mucosal defects there was some evidence $(\mathrm{P}=0.005)$ that patients colonoscoped by experienced endoscopists had $87 \%$ less odds of developing such defects. Moreover, there was evidence that analgesia reduced the odds of developing mucosal defects by $84 \%$.

Conclusion A significant minority of patients with CC have endoscopic findings in colonoscopy. The description of such findings appears to be related to the endoscopist's experience.

Keywords Microscopic colitis, colonoscopy, macroscopic findings, endoscopist training, observational study

Ann Gastroenterol 2017; 30 (3): 1-6

\begin{abstract}
${ }^{a}$ Endoscopy Unit, The Royal Infirmary of Edinburgh, Edinburgh, Scotland, UK (Anastasios Koulaouzidis, Diana E. Yung, Leonidas Bartzis, Ken C. Trimble, John N. Plevris); 'Endoscopy Unit, Skåne University Hospital, Malmö, Sweden (Artur Nemeth, Gabriele Wurm Johansson, Ervin Toth); 'Department of Gastroenterology and Nutrition, Skåne University Hospital, Lund University, Malmö, Sweden (Klas Sjöberg); ${ }^{\mathrm{D} D e p a r t m e n t ~ o f ~ P a t h o l o g y, ~ W e s t e r n ~ G e n e r a l ~ H o s p i t a l, ~ E d i n b u r g h, ~ S c o t l a n d, ~ U K ~(M o r n a ~ M c N e i l l, ~ P a u l ~ F i n e r o n) ; ~}{ }^{\text {FFaculty of }}$ Economics \& Management, Open University of Cyprus, Nicosia, Cyprus (Andry Giannakou); ${ }^{\mathrm{f}}$ Gastroenterology Department, Queen Elizabeth Hospital, Gateshead, England, UK (Raheel Qureshi, Athar Saeed); ' Gastroenterology Department, Hospital General de Tomelloso, Spain (Alfredo J. Lucendo)
\end{abstract}

Conflict of Interest: Dr A Koulaouzidis has received research support from Given Imaging Ltd and SynMed UK, lecture honoraria from Dr Falk Pharma UK, and travel support from Abbott, Dr Falk Pharma UK, Almirall, and MSD. The rest of the authors have no disclosures

Correspondence to: Dr Diana Yung, Endoscopy Unit, The Royal Infirmary of Edinburgh, 51 Little France Crescent, Edinburgh, Scotland, UK EH164SA, Tel.: +44 7789588408, e-mail: diana.e.yung@gmail.com

Received 29 October 2016; accepted 28 December 2016; published online 20 February 2017

DOI: https://doi.org/10.20524/aog.2017.0131 


\section{Introduction}

Microscopic colitis (MC) is diagnosed in approx. $10 \%$ of patients investigated for chronic, non-bloody diarrhea and its etiology remains by and large uncertain [1]. However, the term "microscopic" should not be encouraged, as it can restrict the endoscopist's diagnostic acumen [2]. Collagenous colitis (CC) was independently described by Lindstrom (Sweden) and Freeman (Canada) in the late 1970s [3]; it is one of the 2 main subtypes of MC [1,4]. In 2011, we systematically reviewed the published papers on the endoscopic findings in CC [5]. We recommended the following types of distinct endoscopic findings in CC, with the following visual vocabulary: 1) pseudomembranes; 2) alteration of the vascular submucosal pattern, such as an indistinct appearance of the blood vessels with a variable degree of vasculature pruning, or a crowded, dilated and tortuous capillary network; 3) mucosal abnormalities such as erythema and/or edema/nodularity, or surface textural alteration (evident with or without chromoendoscopy); 4) a continuum of mucosal defects, i.e., mucosal lacerations/tears, including the so-called "catscratch colon" pattern, or fractures usually along the long axis of the colon; and 5) fine, linear cicatricial lines or thick scarlike ridges of the mucosal surface (effects of the healing process of mucosal defects) (Fig. 1 A-E) [5].

However, the reporting of such endoscopic abnormalities remains inconsistent and dependent on local expertise, specialist interest and awareness of the aforementioned endoscopic "visual vocabulary" [6]. Given the ever-increasing workload of modern endoscopy units, recognizing CC on endoscopy has the potential to improve the diagnosis and management of this common disorder [7]. Therefore, the aim of the present study was to confirm the presence of these characteristic macroscopic findings in the largest retrospective cohort to date. The secondary aim was to explore the correlation of these findings with the presenting symptoms, the experience of the endoscopist, the type of bowel purge used and the use of spasmolytics and/or analgesics during the procedure.

\section{Patients and methods}

This is an international, retrospective, observational cohort report of the recorded colonoscopy findings in patients who underwent colonoscopy for the investigation of diarrhea, with or without "plus symptoms", and were eventually diagnosed with CC in four participating centers: two University Hospitals (The Royal Infirmary of Edinburgh, Scotland, UK and the Skåne University Hospital, Malmö, Sweden), and 2 district general hospitals (Queen Elizabeth Hospital, Gateshead, England and the Hospital General de Tomelloso, Spain). "Plus symptoms" were defined as weight loss, abdominal pain, bloating, fatigue, anemia and/or elevated fecal calprotectin. Colonoscopes used were Olympus and Fujinon models, depending on the usual practice in each participating center.

Data were collected from the histopathology registry of the four participating centers. All patients with a histopathological diagnosis of CC between 2008 and 2013 were included. The hospital case notes were reviewed, and information on patients' sex, age, colonoscopy indication(s), experience of the endoscopist (non-training grades: i.e., senior medical or surgical staff, including consultants/specialists/nurse practitioners or trainees), sedation/analgesia/spasmolytics

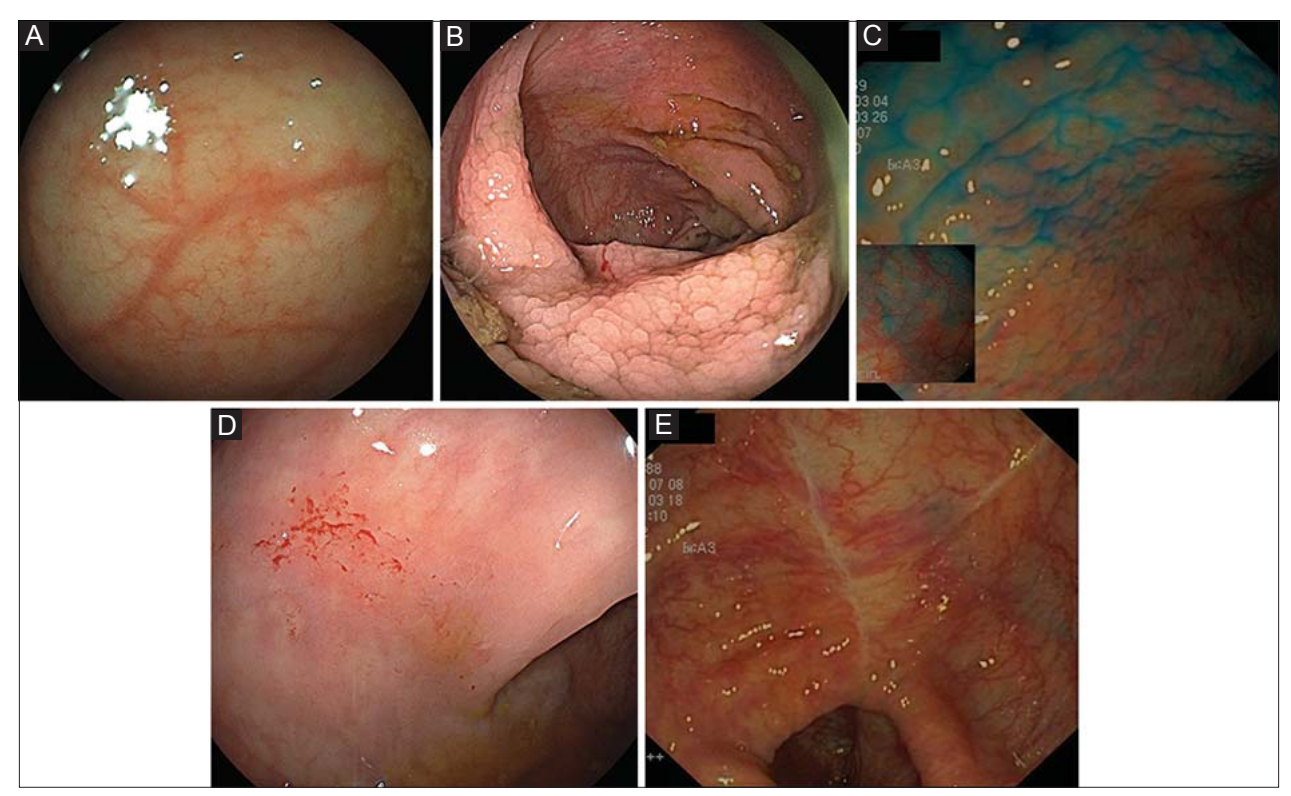

Figure 1 (A) Alteration of the vascular submucosal pattern; indistinct appearance of the blood vessels with a variable degree of vasculature pruning. (B) Mucosal edema/nodularity, evident without chromoendoscopy. (C) Mucosal edema/nodularity, evident with chromoendoscopy. (D) Mucosal lacerations/tears, including the so-called "cat-scratch colon" pattern. (E) Fine, linear cicatricial lines of the mucosal surface (effects of the mucosal healing process of mucosal defects) 
(hyoscine or glucagon) administered during the colonoscopy, type of bowel preparation used (polyethylene glycol [PEG] or sodium picosulphate [SP]), and outcome effect of bowel preparation (good, satisfactory, poor) was extracted. In addition, the endoscopic findings for each case were abstracted.

The classification of endoscopy findings was based on that suggested by Koulaouzidis and Saeed [5]. The criteria to diagnose CC were a relevant clinical history, i.e., protracted (>3 weeks) watery diarrhea, in conjunction with distinctive histopathological features, i.e., a sub-epithelial collagen band $\geq 10 \mu \mathrm{m}$ in thickness in comparison with a normal basal membrane of $<3 \mu \mathrm{m}$. The surface epithelium may show vacuolization, flattening, mucin depletion, and focal detachment from the basement membrane [7]. An increase in intraepithelial lymphocytes was not considered a necessary criterion for the diagnosis of CC.

This study was conducted in accordance with international research ethics guidelines. After review by each local ethics committee, further specific ethical review and approval were not required, as the study was considered to be an evaluation of previously collected data, obtained as part of regular clinical care.

\section{Statistical analysis}

Continuous variables are reported as mean \pm standard deviation (SD). The chi-square test was used to test for statistically significant differences between two or more groups, with a P-value of $<0.05$ considered significant. Where a statistically significant difference was found between more than 2 groups, post-hoc analysis was carried out in an attempt to find the source of the difference.

Logistic regression analysis was used for the correlation of colonoscopy findings: mucosal erythema, edema, cat-scratch colon, mucosal defects (lacerations/tears/fractures), and mucosal scars. The initial model contained a combination of type of laxative preparation, outcomes of bowel preparation, symptoms (diarrhea or diarrhea plus symptoms), endoscopist's experience, and the use of midazolam, Entonox, spasmolytics (hyoscine butylbromide/glucagon), analgesics (morphine/ pethidine/fentanyl) and propofol as potential predictors. Each initial model was subjected to a variable selection procedure using the method of backwards elimination on 200 bootstrap samples drawn from the sample, i.e., the complete data. The bootstrap samples were of the same size as the complete data $(n=276)$.

\section{Results}

During the study period, a total of 607 patients ( 149 men/458 women; mean age $66.9 \pm 12.25$ years) were diagnosed with CC at the 4 participating centers. The full range of endoscopic findings identified is shown in Fig. 1 B-E. The demographics and test indications are shown in Table 1. The colonoscopies
Table 1 Clinical characteristics of patients with collagenous colitis

\begin{tabular}{lc}
\hline Number of cases & \\
Men/women & $149 / 458$ \\
Age (years \pm SD) & $66.9 \pm 12.25$ \\
Indications & \\
Diarrhea only & 466 \\
Diarrhea plus other symptoms & 85 \\
Not available & 19 \\
\hline
\end{tabular}

were carried out by senior medical or surgical endoscopists in $461(76 \%)$ patients. A total of 108/607 (17.8\%) patients had one or more of the endoscopy findings previously described as being suggestive of CC in endoscopy: i.e., mucosal erythema/ edema (mosaic pattern), 91/607 (15\%); linear colonic mucosal defects (lacerations/tears/fractures/cat-scratch mucosa), 12/607 (2\%); or cicatricial mucosal lesions, 5/607 (0.82\%).

- For colonic mucosa erythema, there was no difference in the odds of finding erythema when colonic purge was performed with SP compared to PEG $(\mathrm{P}=0.997)$. However, when the colonoscopy indication was diarrhea plus symptoms, the odds of identifying mucosal erythema were 3.22 times greater than when the sole indication for the procedure was diarrhea alone.

- For colonic mucosal defects (lacerations/tears/fractures), there was weak evidence $(\mathrm{P}=0.097)$ that patients with diarrhea alone had $70 \%$ less chance of developing mucosal defects (lacerations/tears and mucosal fractures). Furthermore, there was some evidence $(\mathrm{P}=0.005)$ that patients colonoscoped by an experienced endoscopist had $87 \%$ lower odds of developing colonic mucosal defects than when colonoscoped by a nurse practitioner or a trainee endoscopist. Moreover, there was evidence that the use of analgesics (in particular morphine) reduced the odds of developing mucosal defects by $84 \%$.

- For colonic mucosal scars and cat-scratch colon, there was insufficient data to detect an effect by any of the variables (Table 2).

There was no reported perforation in either group, i.e., those with and without macroscopic findings. Table 3 shows a comparison of patient characteristics between the 4 participating centers, reflecting differences in local practice and protocols.

\section{Discussion}

Epidemiologic studies show that MC is almost as common as classic inflammatory bowel disease [1], with incidence rates (for CC) of 2.6-10.8/100,000 [1,4,6,8]. MC may be diagnosed in up to $10 \%$ of patients investigated for refractory watery diarrhea [1,9]. A recent study found that endoscopists in academic practice, compared to those working in a private practice setting, were more likely to make an endoscopic diagnosis of MC, possibly due to enhanced diligence, backed 
Table 2 Odds ratio of the macroscopic findings per factor examined

\begin{tabular}{|c|c|c|c|c|}
\hline & OR & SE & $95 \% \mathrm{CI}$ & P-value \\
\hline \multicolumn{5}{|l|}{ Mucosal erythema } \\
\hline (Intercept) & 0.25 & 1.118 & $0.164-0.381$ & 0.215 \\
\hline Phosphate enema & 0.50 & 1.541 & $0.139-1.798$ & 0.653 \\
\hline Sodium picosulphate & 0.12 & 1.24 & $0.1-0.142$ & 0.08 \\
\hline Polyethylene glycol & 1.0 & 1.143 & $0.141-7.02$ & 0.997 \\
\hline Diarrhea plus symptoms (weight loss, abdominal pain, others) & 3.22 & 0.508 & $3.092-3.362$ & 0.021 \\
\hline \multicolumn{5}{|l|}{ Mucosal defects (lacerations/tears and mucosal fractures) } \\
\hline (Intercept) & 1.00 & 0.8158 & $0.202-4.943$ & 0.9991 \\
\hline Diarrhea only & 0.30 & 0.7273 & $0.072-1.244$ & 0.0969 \\
\hline Trainee/nurse endoscopist & 0.13 & 0.7341 & $0.030-0.537$ & 0.005 \\
\hline Analgesic use & 0.16 & 0.7136 & $0.039-0.638$ & 0.0096 \\
\hline \multicolumn{5}{|l|}{ Mucosal scars $(n=4)$} \\
\hline (Intercept) & 0.02 & 1.01 & $0.002-0.136$ & 0.0001 \\
\hline Diarrhea only & 0.28 & 1.42 & $0.017-4.558$ & 0.371 \\
\hline
\end{tabular}

OR, odds ratio; SE, standard error; CI, confidence interval

by pattern recognition, in taking colonic biopsies when investigating altered bowel habits [7]. Interestingly, it was the endoscopists with lower annual endoscopy volumes and physicians with a medical gastroenterology background, compared to surgical endoscopists, who had the highest diagnostic yield for MC [7]. This probably reflects limitations associated with time constraints in offering service-oriented endoscopy in busy units, as well as possible positive awareness bias at more academic-oriented units. In our study, there was no statistically significant difference in the proportion of patients with endoscopic findings when university and district hospitals were compared; however, it must be noted that awareness of $\mathrm{MC}$ is relatively high at all centers in this study.

For a long time it has been a matter of debate as to what drives the rising incidence of $\mathrm{MC}$, and a recent study identified that recognition of the disease and the practice setting of the endoscopists and pathologists involved may be major factors [6]. Dissemination of relevant guidelines has led to an increase in taking biopsies in the appropriate setting; this may have led to the epiphenomenon of increased incidence $[6,9]$. However, the very term MC was coined to group the 2 colitides that are considered to present with typical clinical symptoms of chronic watery, non-bloody, and refractory diarrhea, but little in the way of macroscopic findings during colonoscopy $[1,2]$.

Recently, the functionality of this term has been questioned on several occasions, especially with the advent of new, high definition endoscopes, with or without the application of chromoendoscopy or endomicroscopy [2,5,10-12]. Although there is no feature that could be seen as truly pathognomonic of MC, or CC specifically, on colonoscopy, linear mucosal defects [5] or fractures of the colon mucosa have a higher sensitivity and specificity than cat-scratch colon, mucosal cobblestone or subtle changes of the surface mucosa vasculature $[5,10,11,13-16]$. Nevertheless, the official statement of the European Microscopic Colitis Group considers that colonoscopy is 'normal or near-normal' [1].

The Edinburgh experience shows that a significant minority of patients who are eventually diagnosed with CC [17] have one or more of the findings that have been described as (endoscopically) suggestive of MC [5]. Colonic perforation has been described in CC and remains a serious concern, especially when deep mucosal tears appear $[15,18]$. Mucosal tears/fractures are dramatic endoscopic findings, and hence unlikely to be missed. In our multi-center cohort, no endoscopic perforation occurred following colonoscopy and biopsy. Furthermore, there was no difference in the reporting of macroscopic findings between the participating centers $(\mathrm{P}=0.9)$, although awareness levels were high in all participating units.

The fact that the prevalence of mucosal lacerations is higher in the non-analgesia group may reflect the need for more aggressive air distension for further scope insertion, due to a cycle of discomfort, agitation, and endoscopist stress. This could result in more radial distension of the colon and the lack of compliance causes detachment of the mucosa from deeper submucosal layers, especially during bowel wall stretching, with air insufflation on colonoscopy or even spontaneously during defecation [19].

There are, of course, certain limitations to this study, stemming from its retrospective nature and therefore the lack of a control group, potential heterogeneity of the endoscopic/ histological findings and reporting criteria, the use of different type of analgesics and of different colonoscope models. Furthermore, recall bias is to be expected, as senior physicians were aware of potential subtle abnormalities and suspected the diagnosis upfront. Nevertheless, our study provides insight into the frequency of macroscopic findings in CC in unselected patients. From this point of view, it can be argued that the 
Table 3 Comparison of patient characteristics between centers

\begin{tabular}{|c|c|c|c|c|c|}
\hline Center & $\begin{array}{l}\text { Scotland, UK } \\
\text { (university) }\end{array}$ & $\begin{array}{l}\text { Malmö, Sweden } \\
\text { (university) }\end{array}$ & $\begin{array}{l}\text { Gateshead, UK } \\
\text { (district) }\end{array}$ & $\begin{array}{c}\text { Tomelloso, } \\
\text { Spain (district) }\end{array}$ & Chi-square test ${ }^{*}$ \\
\hline Total number of patients & 208 & 203 & 166 & 5 & - \\
\hline \multicolumn{6}{|l|}{ Indications } \\
\hline Diarrhea only (\%) & $161(79.3)$ & $168(82.8)$ & $120(76.4)$ & 0 & \multirow[t]{4}{*}{$\begin{array}{l}\chi^{2}=4.69 \\
P=0.32\end{array}$} \\
\hline Diarrhea plus (\%) & $25(12.3)$ & $26(12.8)$ & $27(17.2)$ & 0 & \\
\hline Other $(\%)$ & $17(8.4)$ & $9(4.4)$ & $10(6.4)$ & 0 & \\
\hline Unknown & 5 & 0 & 9 & 5 & \\
\hline \multicolumn{6}{|l|}{ Endoscopist experience } \\
\hline Experienced (\%) & $130(62.5)$ & $196(96.6)$ & $117(70.5)$ & $5(100)$ & \multirow[t]{3}{*}{$\begin{array}{l}\text { Experienced vs } \\
\text { others: } \\
\chi^{2}=71.0 \\
\mathrm{P}<0.05 \\
\text { (significant } \\
\text { differences between } \\
\text { all } 3 \text { centers analyzed) }\end{array}$} \\
\hline Trainee (\%) & $34(16.3)$ & 0 & $24(14.5)$ & 0 & \\
\hline Nurse endoscopist (\%) & $44(21.2)$ & $7(3.4)$ & $18(10.8)$ & 0 & \\
\hline \multicolumn{6}{|l|}{ Analgesia and/or sedation given } \\
\hline No medication (\%) & $22(10.6)$ & $141(69.5)$ & $118(71.1)$ & 0 & \\
\hline $\begin{array}{l}\text { Analgesia or sedation given } \\
(\%)\end{array}$ & $186(89.4)$ & $62(30.5)$ & $48(28.9)$ & $5(100)$ & $\begin{array}{l}\mathrm{X}^{2}=189.3 \\
\mathrm{P}<0.05 \\
\text { (significance from } \\
\text { Edinburgh) }\end{array}$ \\
\hline Midazolam (\%) & $174(83.7)$ & $52(25.6)$ & $39(23.5)$ & 0 & - \\
\hline Ketobemidone (\%) & 0 & $52(25.6)$ & $2(1.2)$ & 0 & - \\
\hline Pethidine (\%) & 0 & 0 & $5(3.0)$ & 0 & - \\
\hline Fentanyl (\%) & $177(85.1)$ & 0 & $1(0.6)$ & 0 & - \\
\hline Entonox (\%) & 0 & 0 & $6(3.6)$ & 0 & - \\
\hline Buscopan (\%) & $8(3.8)$ & $10(4.9)$ & $21(12.7)$ & 0 & - \\
\hline Morphine (\%) & 0 & $5(2.5)$ & 0 & 0 & - \\
\hline $\begin{array}{l}\text { General anesthesia/ propofol } \\
\text { (\%) }\end{array}$ & 0 & $3(1.5)$ & $1(0.6)$ & $5(100)$ & - \\
\hline \multicolumn{6}{|l|}{ Quality of bowel preparation } \\
\hline Poor (\%) & $21(10.1)$ & $3(3.6)$ & $2(3.2)$ & 0 & \multirow{3}{*}{$\begin{array}{l}\mathrm{X}^{2}=128.5 \\
\mathrm{P}<0.05 \\
\text { (significant } \\
\text { differences between } \\
\text { all } 3 \text { centers analyzed) }\end{array}$} \\
\hline Satisfactory (\%) & $78(37.5)$ & $6(7.1)$ & $60(95.2)$ & 0 & \\
\hline Good (\%) & $109(52.4)$ & $75(89.3)$ & $1(1.6)$ & 0 & \\
\hline Unknown & 0 & 119 & 103 & 5 & - \\
\hline \multicolumn{6}{|l|}{ Colonoscopy findings } \\
\hline No macroscopic findings (\%) & $183(88.0)$ & $153(75.4)$ & $140(84.3)$ & $5(100)$ & \multirow{4}{*}{$\begin{array}{l}\text { Findings vs no } \\
\text { findings: } \\
\chi^{2}=11.9 \\
\mathrm{P}<0.05 \\
\text { (significant } \\
\text { differences between } \\
\text { all } 3 \text { centers analyzed) } \\
\text { University vs district } \\
\text { hospitals: } \\
\chi^{2}=0.55 \\
\mathrm{P}=0.46\end{array}$} \\
\hline Mucosal erythema/edema (\%) & $16(7.7)$ & $49(24.1)$ & $22(13.3)$ & 0 & \\
\hline $\begin{array}{l}\text { Linear colonic mucosal } \\
\text { defects }(\%)\end{array}$ & $12(5.8)$ & $2(1.0)$ & $3(1.8)$ & 0 & \\
\hline $\begin{array}{l}\text { Cicatricial lesions/ scarring } \\
(\%)\end{array}$ & $2(1.0)$ & $1(0.5)$ & $1(0.6)$ & 0 & \\
\hline
\end{tabular}

Percentages are given as a proportion of patients where the information is known. Diarrhea plus symptoms are defined as weight loss, abdominal pain, bloating, fatigue, anemia and/or raised fecal calprotectin. ${ }^{*}$ The chi-square tests compared only the centers from Scotland, Malmö and Gateshead, because of the low number of patients from Tomelloso 


\section{Summary Box}

\section{What is already known:}

- Collagenous colitis (CC) is a clinical syndrome of chronic watery diarrhea with adverse effects on patients' quality of life

- The diagnosis of CC remains reliant on histology

- Certain colonoscopic findings are suggestive of CC

- The time lag between endoscopy and histological confirmation of a diagnosis can delay initiation of treatment

\section{What the new findings are:}

- Macroscopic findings suggestive of CC occur independently of the type of bowel preparation used

- Endoscopist experience had a positive correlation with recognition of characteristic macroscopic appearances of CC

- Patients with additional symptoms other than diarrhea were 3 times more likely to have macroscopic findings than patients with diarrhea alone

- Mucosal lacerations occurred more frequently in patients not given analgesia for colonoscopy

present study further explores the importance of being aware of this phenomenon, in addition to the other findings.

In conclusion, endoscopic findings are recognized with increased frequency in patients with CC [20]. However, the use of new, high-definition videocolonoscopes allows new insight into this entity. Factors associated with the recognition of these findings are associated with clinical symptoms as well as procedural factors.

\section{References}

1. Münch A, Aust D, Bohr J, et al; European Microscopic Colitis Group (EMCG). Microscopic colitis: Current status, present and future challenges: statements of the European Microscopic Colitis Group. J Crohns Colitis 2012;6:932-945.

2. Langner C, Aust D, Ensari A, et al; Working Group of Digestive
Diseases of the European Society of Pathology (ESP) and the European Microscopic Colitis Group (EMCG). Histology of microscopic colitis-review with a practical approach for pathologists. Histopathology 2015;66:613-626.

3. Freeman HJ, Weinstein WM, Shnitka TK, et al. Watery diarrhea syndrome associated with a lesion of the colonic basement membrane-lamina propria interface. Ann $R$ Coll Phys Surg Can 1976;9:45.

4. Bohr J, Wickbom A, Hegedus A, Nyhlin N, Hultgren Hörnquist E, Tysk C. Diagnosis and management of microscopic colitis: current perspectives. Clin Exp Gastroenterol 2014;7:273-284.

5. Koulaouzidis A, Saeed AA. Distinct colonoscopy findings of microscopic colitis: not so microscopic after all? World $J$ Gastroenterol 2011;17:4157-4165.

6. Storr MA. Microscopic colitis: epidemiology, pathophysiology, diagnosis and current management-an update 2013. ISRN Gastroenterol 2013;2013:352718.

7. Andrews CN, Beck PL, Wilsack L, Urbanski SJ, Storr M. Evaluation of endoscopist and pathologist factors affecting the incidence of microscopic colitis. Can J Gastroenterol 2012;26:515-520.

8. Vigren L, Olesen M, Benoni C, Sjöberg K. An epidemiological study of collagenous colitis in southern Sweden from 2001-2010. World J Gastroenterol 2012;18:2821-2826.

9. Bateman AC, Patel P. Lower gastrointestinal endoscopy: guidance on indications for biopsy. Frontline Gastroenterol 2014;5:96-102.

10. Cimmino DG, Mella JM, Pereyra L, et al. A colorectal mosaic pattern might be an endoscopic feature of collagenous colitis. J Crohns Colitis 2010;4:139-143.

11. Suzuki G, Mellander MR, Suzuki A, et al. Usefulness of colonoscopic examination with indigo carmine in diagnosing microscopic colitis. Endoscopy 2011;43:1100-1104.

12. Kiesslich R, Hoffman A, Goetz M, et al. In vivo diagnosis of collagenous colitis by confocal endomicroscopy. Gut 2006;55:591-592.

13. Sato S, Benoni C, Tóth E, Veress B, Fork FT. Chromoendoscopic appearance of collagenous colitis-a case report using indigo carmine. Endoscopy 1998;30:S80-S81.

14. Koulaouzidis A. Mucosal scars in collagenous colitis. Gastrointest Endosc 2010;71:221-222.

15. Koulaouzidis A, Henry JA, Saeed AA. Mucosal tears can occur spontaneously in collagenous colitis. Endoscopy 2006;38:549.

16. McDonnell WM, Loura F, Pointon MJ, Greenson JK. Cat scratch colon. Endoscopy 2007;39:459-461.

17. Smirnidis A, Trimble KC, Lessels A, Koulaouzidis A. Endoscopic findings in collagenous colitis; not always microscopic. Gut 2012;61:A154.

18. Hussain Z, Kelly S, Clarke A, Adams S, Miller G. Colonic perforation in collagenous colitis: a systematic review of a rare complication and guidance on management. Surg Endosc 2010;24:2930-2934.

19. Madalinski M, Koulaouzidis A. Collagenous colitis with mucosal tears in two proton pump inhibitors and non-steroidal naive patients who developed metachronous cancer. J Dig Dis 2013;14:51-53.

20. Yung DE, Koulaouzidis A, Fineron P, Plevris JN. Microscopic colitis: a misnomer for a clearly defined entity? Endoscopy 2015;47:754-757. 